\title{
Technical Note: Description and assessment of a nudged version of the new dynamics Unified Model
}

\author{
P. J. Telford, P. Braesicke, O. Morgenstern, and J. A. Pyle \\ University of Cambridge, Cambridge NCAS-Climate, UK \\ Received: 4 October 2007 - Published in Atmos. Chem. Phys. Discuss.: 27 November 2007 \\ Revised: 26 February 2008 - Accepted: 28 February 2008 - Published: 20 March 2008
}

\begin{abstract}
We present a "nudged" version of the Met Office general circulation model, the Unified Model. We constrain this global climate model using ERA-40 re-analysis data with the aim of reproducing the observed "weather" over a year from September 1999. Quantitative assessments are made of its performance, focusing on dynamical aspects of nudging and demonstrating that the "weather" is well simulated.
\end{abstract}

\section{Introduction}

The ability to mimic the real state of the atmosphere, the "weather", in a climate model is useful for studying processes on short time scales for which monthly means contain only a limited amount of information. Newtonian relaxation or "nudging" is a method that adjusts dynamical variables of general circulation models (GCM) towards meteorological re-analysis data, providing a realistic representation of the weather.

Jeuken et al. (1996) were the first to consider applying the technique to the validation of GCMs, adding nudging to the ECHAM GCM. This remains the most complete description of a nudged model, though others exist, including the LMDZ (Hauglustaine et al., 2004), GISS (Schmidt et al., 2006) and CCSR/NIES AGCM (Takemura et al., 2000) models. The technique has been widely adopted to study processes where capturing the daily variability of phenomena is important. Examples include examining the behaviour of chemical tracers (van Aalst et al., 2004), and studying the properties of clouds (Dean et al., 2006).

The climate model which we nudge is the Met. Office GCM, the Unified Model (henceforth the UM) (Staniforth et al., 2005). There have been applications of the nudging

Correspondence to: P. J. Telford (paul.telford@atm.ch.cam.ac.uk) technique in earlier versions of this model, to study clouds (Flowerdew et al., 2008 ${ }^{1}$ ) and to include a realistic quasi biennial oscillation (Pyle et al., 2005). We describe the first implementation of the nudging technique to the new nonhydrostatic version of the UM, the "New Dynamics" UM, and evaluate the performance of the system for a 12 month integration starting in September 1999.

After a brief description of the model, we provide a quantitative assessment of its performance with respect to the ERA-40 re-analysis data. The RMSE, bias and correlations in space and time between the model and the ERA-40 data are calculated, with and without nudging, for variables that are directly adjusted by the nudging and variables adjusted indirectly. After varying a few key parameters we conclude by considering future prospects for the model.

\section{Model description}

The Model is based upon version 6.1 of the UM (Staniforth et al., 2005). The dynamical prognostic variables adjusted by nudging are potential temperature, $\theta$, zonal wind, $u$, and meridional wind, $v$. The configuration used has

- a horizontal resolution of $3.75^{\circ} \times 2.5^{\circ}$ in longitude and latitude.

- 60 hybrid height levels in the vertical, from the surface up to a height of $84 \mathrm{~km}$.

- a dynamical time-step of $20 \mathrm{~min}$.

The sea surface temperatures and sea ice coverage are prescribed from the HADISST dataset (Rayner et al., 2002). The version of the model used was known to have temperature biases, the most notable being a warm bias in the lower

\footnotetext{
${ }^{1}$ Flowerdew, J., Lawrence, B. N., and Andrews, D.: The use of nudging and feature tracking to evaluate climate model cloud, Climate Physics, in review, 2008.
} 
stratosphere, especially over the poles, and around the tropical tropopause. The initial conditions are taken from the default climate integration file.

We add a module that reads global re-analysis data and "nudges" the model towards it. The re-analysis data used here is from the ECMWF ERA-40 dataset (ECMWF, 1996; Uppala et al., 2005). Although there are some weaknesses in the ERA-40 analysis, such as an overly strong BrewerDobson Circulation (Uppala et al., 2005), they have been widely used (Jeuken et al., 1996; Hauglustaine et al., 2004) and are adequate to assess the performance of the nudging technique.

\subsection{Data utilised}

The ECMWF ERA-40 re-analysis data is used to constrain the model. It is available at six hourly intervals on a $1^{\circ} \times 1^{\circ}$ grid. The variables taken for nudging are temperature, $T$, zonal wind, $u$, and meridional wind, $v$. The ERA-40 data is pre-processed horizontally by bi-linearly interpolating on to the model grid.

At run-time the data is linearly interpolated on to the model time-steps. Previous studies indicate that there is no advantage to using more complex interpolations over these time-scales (Brill et al., 1991). No explicit truncation, like that used by Jeuken et al. (1996), is applied. The conversion to a coarser resolution and the smooth linear interpolation in time should favour slow and large scale horizontal motions, removing most "noise" from the data.

To obtain the UM prognostic variables, $T$ is converted to $\theta$. The variables, $u, v$ and $\theta$, are interpolated linearly in logarithm of pressure, $\ln (P)$, from the ECMWF hybrid pressure levels to the UM hybrid height levels. The orographies in the UM and ECMWF models, although based on similar datasets, are different due to different processing procedures for different grids. These differences can be as large as hundreds of metres in the Andes and Antarctica. They can produce errors in the interpolation from the ECMWF to UM model levels due to the vertical structure of the model levels being represented differently in the two models.

A solution considered was the use of the ECMWF orography in the nudged UM model. However this would create problems; apart from the question of how to interpret a spectral orography in a grid-point model, it could disrupt other aspects of the model such as orographic gravity wave drag. The errors in the interpolation occur predominantly in the lowest few model levels, which are not utilised by the nudging. The small improvement on a few levels used by the nudging was not felt to justify the problems that using the ECMWF orography would cause. Although using the Met Office analysis data (Lorenc et al., 1999) would remove any differences in orography they were not used as they are only available once a day.

\subsection{Set up of the nudging}

The ERA-40 data is included into the model by the addition of non-physical relaxation terms to the model equations. The rate of change in a variable, $X$, is obtained from

$\frac{\delta X}{\delta t}=F_{m}(X)+G\left(X_{\text {ana }}-X\right)$,

where $F_{m}$ is the rate of change in the variable due to all other factors, $X_{\text {ana }}$ is the value of the variable in the ERA-40 data and $G$ is the relaxation parameter (Jeuken et al., 1996). As we are working in discrete time-steps this equation is implemented explicitly as

$\Delta X=F_{m t}(X)+(G \Delta t)\left(X_{\text {ana }}-X\right)$,

where $F_{m t}$ is the change of the variable due to all other factors over the dynamical time-step and $\Delta t$ is the dynamical time-step size.

The choice of relaxation parameter, although arbitrary, is important, as if it is too small nudging is ineffective, yet too large and the model becomes unstable. The value chosen is the "natural" one of $\frac{1}{6} \mathrm{~h}^{-1}$, the time spacing of the ERA-40 data. This also lies within the range of relaxation parameters used by other models (Jeuken et al., 1996; Hauglustaine et al., 2004; Schmidt et al., 2006).

The variation of the relaxation parameter with UM hybrid height level is displayed in Fig. 1. The average ECMWF temperature, as a function of UM hybrid height level, is included for orientation. The temperature is taken from the ERA-40 data in October 1999 and interpolated onto the UM hybrid height levels.

Nudging is not applied to all levels; it is not applied on levels which utilise data from the topmost ECMWF hybrid pressure levels, or in the bottommost levels that constitute the boundary layer. This results in no nudging being applied above level $50(\sim 48 \mathrm{~km})$, with a linear increase in $G$ from 0 at level 50 to its full value at level $45(\sim 38 \mathrm{~km})$, or below level $12(\sim 2.9 \mathrm{~km})^{2}$, with a linear increase in $G$ from 0 at level 12 to its full value at level $15(\sim 4.5 \mathrm{~km})$. The effect of using different relaxation parameters and vertical ranges is discussed in Sect. 4.

\section{Assessment of model performance}

The model was run for a year starting from 1 September 1999. From this simulation three periods are selected for more detailed analysis; October, January and July. During these periods a suite of statistical tools is used to determine the size of any differences and correlations between the model and the ERA- 40 data.

The main assessment consists of a series of comparisons of variables, including some which are nudged directly $(u$

\footnotetext{
${ }^{2}$ The levels are hybrid height levels and their exact values depend on the orography.
} 
and $\theta$ ), and some which are not (surface pressure, $P_{s}$, and specific humidity, $q$ ). The comparison examines the size and variation of differences between the model and the ERA-40 data. In addition derived quantities, such as precipitation and vertical wind are compared. To establish that nudging does not predominate over the physical tendencies in the model, the effect of nudging with respect to other factors, are studied.

\subsection{Comparison of dynamical quantities}

The first assessment of the model performance is to compare dynamical quantities between the model and the ERA40 data. The following variables are studied, the first two are directly adjusted, the latter two not: potential Temperature $(\theta)$, zonal wind $(u)$, specific humidity $(q)$ and surface pressure $\left(P_{S}\right)$. This is done using a series of quantitative assessments:

- The root mean squared error (RMSE); obtained by taking the root mean square difference between the model and ERA-40 data. The value on a particular model level is obtained by averaging the differences over time and over all grid-points on that level. It is a measure of the magnitude of differences in the observable.

- Bias; obtained by taking the difference in the monthly mean of the observable between the model and the ERA-40 data. The value on a particular model level is obtained by averaging over all grid-points on that level. It reflects any systematic differences between them.

- Correlation in time (TC); determined by calculating the correlation in time between the observable in the model and the ERA-40 data for each grid-point. The value on a particular model level is obtained by averaging over all grid-points on that level. It is a measure of how well the model represents the variation in time of the ERA-40 data.

- Correlation in space (SC); determined by calculating the spatial correlation between the observable in the model and the ERA-40 data over a model level and averaging over time. It provides a measure of how well the model represents the variation in space of the ERA-40 data.

The variable used to determine the correlation is Pearson's rank coefficient. The time series consisted of one set of values taken every day at midnight UTC. For all variables, excluding surface pressure, the assessments are calculated on levels representing regions of the atmosphere. In the case of surface pressure they are determined for the surface level alone. The chosen levels are

- Level 6, corresponding to a height of around $700 \mathrm{~m}$, representing the boundary layer.
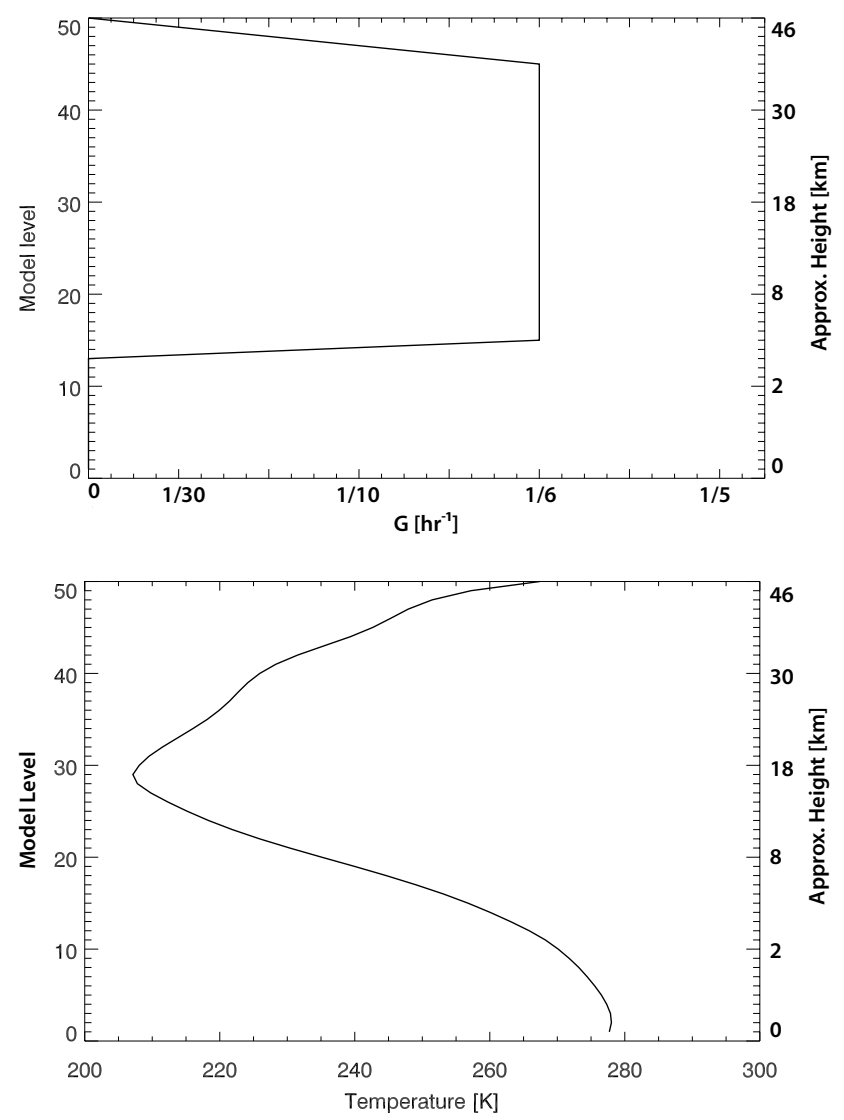

Fig. 1. Relaxation parameter, $G$, (left) and average temperature (right) as a function of UM hybrid height level.

- Level 16, corresponding to a height of around $5 \mathrm{~km}$, representing the free troposphere.

- Level 29, corresponding to a height of around $15 \mathrm{~km}$, which is around the tropopause, as shown in Fig. 1, and the region in the polar stratosphere where polar stratospheric clouds form.

- Level 35, corresponding to a height of around $20 \mathrm{~km}$, representing the lower stratosphere.

The ERA-40 data is obtained on UM hybrid height levels by interpolating linearly in $\ln P$ for each model time-step.

The assessments are performed over three time periods, in October, January and July, with and without the nudging module added. The unadjusted results are taken from three separate integrations each initialised at the start of the month from the output of the nudged integration, so that any differences cannot be attributed to starting conditions.

The values for October are given in Table 1 with nudging and Table 2 without. The values from January and July are not significantly different and so are not displayed. 
Table 1. Quantitative assessment of model performance in October 1999 with nudging.

\begin{tabular}{cccccc}
\hline & Level & Mean and Bias & RMSE & TC & SC \\
\hline \multirow{4}{*}{$\theta$} & 6 & $285.5+0.5 \mathrm{~K}$ & $2.5 \mathrm{~K}$ & 0.75 & 0.98 \\
& 16 & $306.5+0.0 \mathrm{~K}$ & $0.6 \mathrm{~K}$ & 0.94 & 1.00 \\
& 29 & $416.2+0.0 \mathrm{~K}$ & $1.1 \mathrm{~K}$ & 0.98 & 1.00 \\
& 35 & $607.4-0.1 \mathrm{~K}$ & $1.9 \mathrm{~K}$ & 0.95 & 1.00 \\
& 6 & & & & \\
4 & 16 & $6.06+0.00 \mathrm{~ms}^{-1}$ & $1.45 \mathrm{~ms}^{-1}$ & 0.78 & 0.91 \\
& 29 & $12.93-0.03 \mathrm{~ms}^{-1}$ & $1.17 \mathrm{~ms}^{-1}$ & 0.98 & 1.00 \\
& 35 & $10.38+0.00 \mathrm{~ms}^{-1}$ & $1.37 \mathrm{~ms}^{-1}$ & 0.98 & 1.00 \\
& 6 & & & & \\
\multirow{4}{*}{$q$} & 16 & $1.0+0.0 \mathrm{~g} / \mathrm{kg}$ & $0.7 \mathrm{~g} / \mathrm{kg}$ & 0.76 & 0.86 \\
& 29 & $2.4+0.0 \mathrm{mg} / \mathrm{kg}$ & $0.3 \mathrm{mg} / \mathrm{kg}$ & 0.26 & 0.84 \\
& 35 & $2.5-0.1 \mathrm{mg} / \mathrm{kg}$ & $0.3 \mathrm{mg} / \mathrm{kg}$ & -0.12 & 0.24 \\
$P_{S}$ & 0 & $963.7+0.3 \mathrm{hPa}$ & $14.6 \mathrm{hPa}$ & 0.92 & 0.99 \\
\hline
\end{tabular}

Table 2. Quantitative assessment of model performance in October 1999 without nudging.

\begin{tabular}{cccccc}
\hline & Level & Mean and Bias & RMSE & TC & SC \\
\hline \multirow{4}{*}{$\theta$} & 6 & $285.0+0.1 \mathrm{~K}$ & $4.5 \mathrm{~K}$ & 0.26 & 0.95 \\
& 16 & $305.3-1.2 \mathrm{~K}$ & $5.3 \mathrm{~K}$ & 0.20 & 0.94 \\
& 29 & $420.1+3.4 \mathrm{~K}$ & $9.9 \mathrm{~K}$ & 0.23 & 0.95 \\
& 35 & $608.9+2.2 \mathrm{~K}$ & $11.0 \mathrm{~K}$ & 0.26 & 0.91 \\
& 6 & & & & \\
4 & 16 & $6.75-0.21 \mathrm{~ms}^{-1}$ & $7.82 \mathrm{~ms}^{-1}$ & 0.14 & 0.54 \\
& 29 & $12.32-0.46 \mathrm{~ms}^{-1}$ & $9.49 \mathrm{~ms}^{-1}$ & 0.19 & 0.62 \\
& 35 & $10.12-0.21 \mathrm{~ms}^{-1}$ & $9.53 \mathrm{~ms}^{-1}$ & 0.28 & 0.81 \\
& 6 & & & & 0.35 \\
& 16 & $0.9-0.1 \mathrm{~g} / \mathrm{kg}$ & $1.1 \mathrm{~g} / \mathrm{kg}$ & 0.19 & 0.63 \\
& 29 & $2.5+0.1 \mathrm{mg} / \mathrm{kg}$ & $0.4 \mathrm{mg} / \mathrm{kg}$ & -0.06 & 0.81 \\
& 35 & $2.5-0.1 \mathrm{mg} / \mathrm{kg}$ & $0.3 \mathrm{mg} / \mathrm{kg}$ & -0.14 & 0.28 \\
& & & & & \\
$P_{S}$ & 0 & $964.8+1.4 \mathrm{hPa}$ & $17.6 \mathrm{hPa}$ & 0.17 & 0.98 \\
\hline
\end{tabular}

\subsubsection{Magnitude of differences}

The RMSE represents the magnitude of the difference between the model and the ERA-40 data. The addition of nudging reduces the RMSE in all of the assessments made, as shown in Tables 1 and 2, giving evidence that nudging produces better agreement with the ERA-40 data. Figure 2 plots the percentage RMSE of $\theta$ between the model with nudging and the ERA-40 data as a function of UM hybrid height level for the three assessment periods. This shows that the RMSE varies little over the height range nudged and over time.

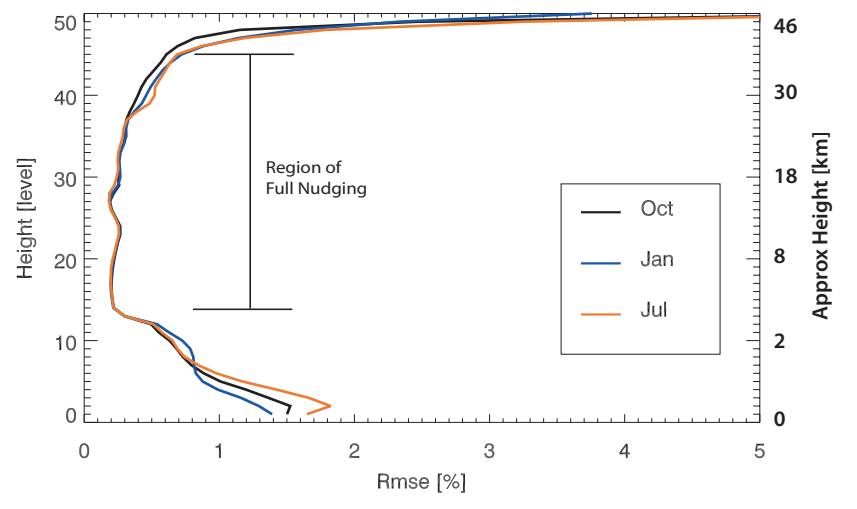

Fig. 2. RMSE in $\theta$ between the model, with nudging, and the ERA40 data as a function of UM hybrid height level for the three periods assessed.

The rapid increase in the percentage RMSE towards the top of the model, above the region where nudging is applied, reflects the different treatment of the upper stratosphere between the UM and ECMWF models.

The increase in the RMSE towards the bottom of the model has two components. The increase below level $13(\sim 3.5 \mathrm{~km})$ is produced by the fading out of nudging. The increase below level $6(\sim 700 \mathrm{~m})$ is caused by different factors. This is partly a result of errors in the vertical interpolation used, but is mainly produced by differences over land and ice in the winter.

This can more clearly be seen in Fig. 3, which plots the absolute RMSE in $\theta$ for the UM hybrid height level closest to the surface ( $20 \mathrm{~m}$ above the surface) in July. The largest values occur over Antarctica. In January the RMSE is smaller in Antarctica but larger in the Arctic. These differences probably reflect differences in the heat transfer between the surface and the atmosphere between the UM and ECMWF models. Smaller increases in RMSE can be observed in mountainous regions, such as the Himalayas and the Andes. The low values of RMSE over the Oceans close to the surface, as shown in this figure, demonstrate the benefit of prescribing observed climatological sea surface temperatures.

The RMSE of $u$ shows a similar decrease when nudging is added to the model. The RMSE of $q$ is reduced by nudging, but not so markedly as the RMSE of $u$ or $\theta$. This is to be expected as, though nudging synchronises the large scale dynamics in the model to those in the ERA-40 data, the model physics that determines $q$ is still different. In addition a small amount of noise may still be present in the data nudged to. The representation of $q$ in the stratosphere also suffers from unrealistic initial conditions and, as water content varies slowly here, it is unaffected by nudging in this integration. The RMSE of $P_{s}$ shows a small decrease with the addition of nudging, but as the RMSE is dominated by differences in the orography between the ERA-40 data and the model it is little affected by nudging. 


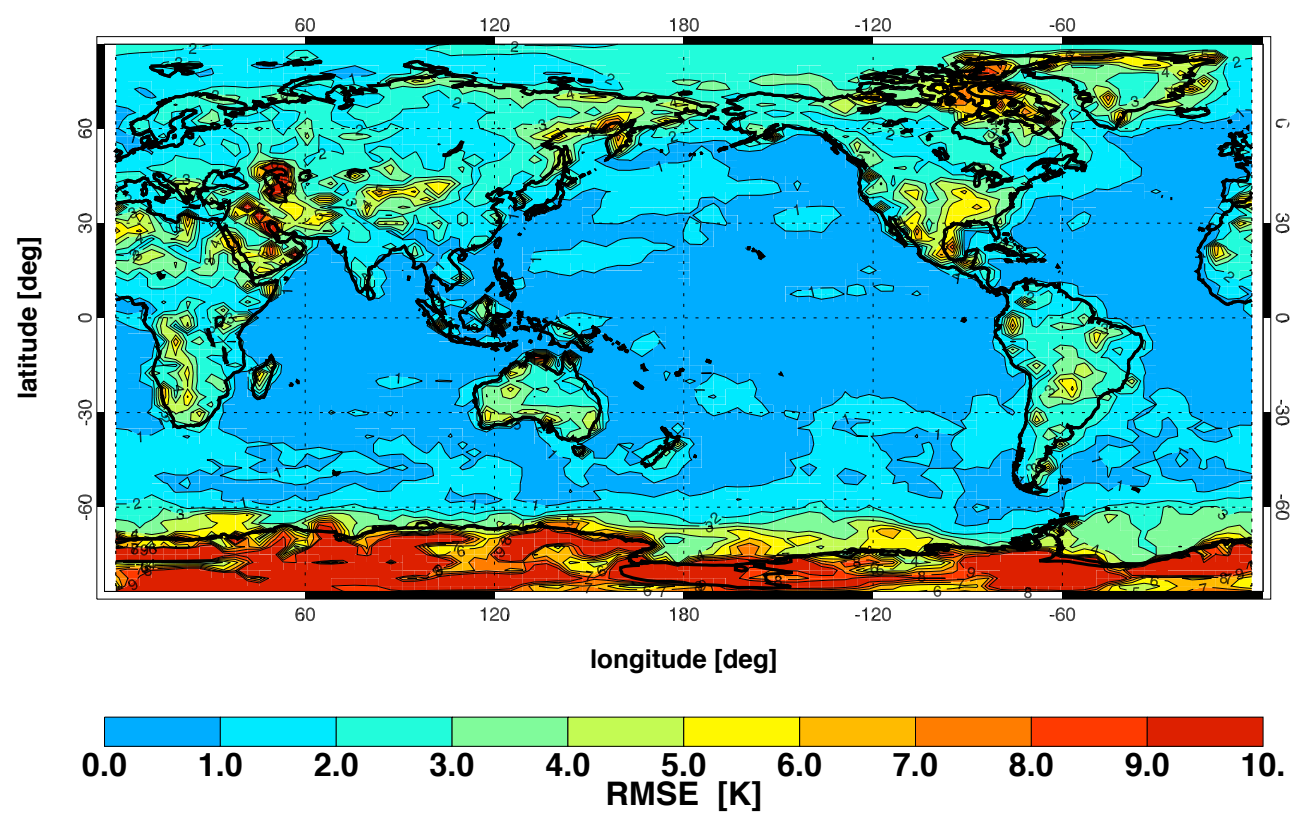

Fig. 3. RMSE in $\theta$ between the model, with nudging, and the ERA-40 data for the lowest UM hybrid height level in July 2000.

In general the RMSE in all variables arise from a combination of systematic differences and from incorrectly reproducing the temporal variation of the system. These factors are investigated separately by looking at the biases and correlations between the model and the ERA-40 data.

\subsubsection{Biases in the model}

The biases reflect any systematic differences between the model and the ERA- 40 data. They are calculated as monthly mean differences between the ERA-40 data and the model, averaged over each model level.

The most notable biases without nudging in the model are those in $\theta$, which are mostly removed by the addition of nudging (Fig. 4). Nudging removes the biases in the upper troposphere and lower stratosphere, corresponding to the smaller biases observed on the three upper levels in Tables 1 and 2. The removal of these biases is crucial to the modelling of phenomena such as polar stratospheric cloud (PSC) formation and dehydration of air passing through the tropopause.

The small bias in level $6(\sim 700 \mathrm{~m})$ of the nudged model, located over Antarctica, is attributed to increased cloudiness produced by nudging. The mechanism producing this extra cloudiness is not fully understood. The smaller RMSE with nudging indicates that the addition of nudging still provides a better description of the ERA-40 data. The addition of nudging also reduces biases in $u, P_{s}$ and, to a lesser degree, $q$ (Tables 1 and 2).

\subsubsection{Representing variability}

As well as systematic differences there are differences in the variation of the observables over space and time. The ability of the model to produce the same variation as the ERA-40 data is assessed by the TC and the SC. A comparison between Tables 1 and 2 shows that the addition of nudging increases the correlation between the model and the analyses, with the increase in TC being larger.

Figure 5 shows the TC between the model and the ERA40 data for $u$, with and without the addition of nudging, as a function of UM hybrid height level. The TC varies smoothly with height both with and without nudging. The addition of nudging greatly increases the correlation, though TC decreases below where nudging is cut-off and declines again near the surface where there are errors in the vertical interpolation of the ERA-40 data. Without nudging the model and the ERA-40 data are very poorly correlated in the troposphere. In the stratosphere the unadjusted model is slightly better at reproducing the variability than in the troposphere.

The performance of the model also varies spatially, see for example the TC for $\theta$ on UM hybrid height level $6(\sim 700 \mathrm{~m})$ (Fig. 6). The TC is high in the extra-tropics, and lower in the tropics, in agreement with Jeuken et al. (1996). The lower TC in this region is not a large problem as the scale of variability is small, as can be seen by the low values of RMSE in this region in Fig. 3.

A further illustration of the success of the nudged model in reproducing the variation is given in Fig. 7. The large differences in $P_{S}$, a variable that is not adjusted, over the Southern 


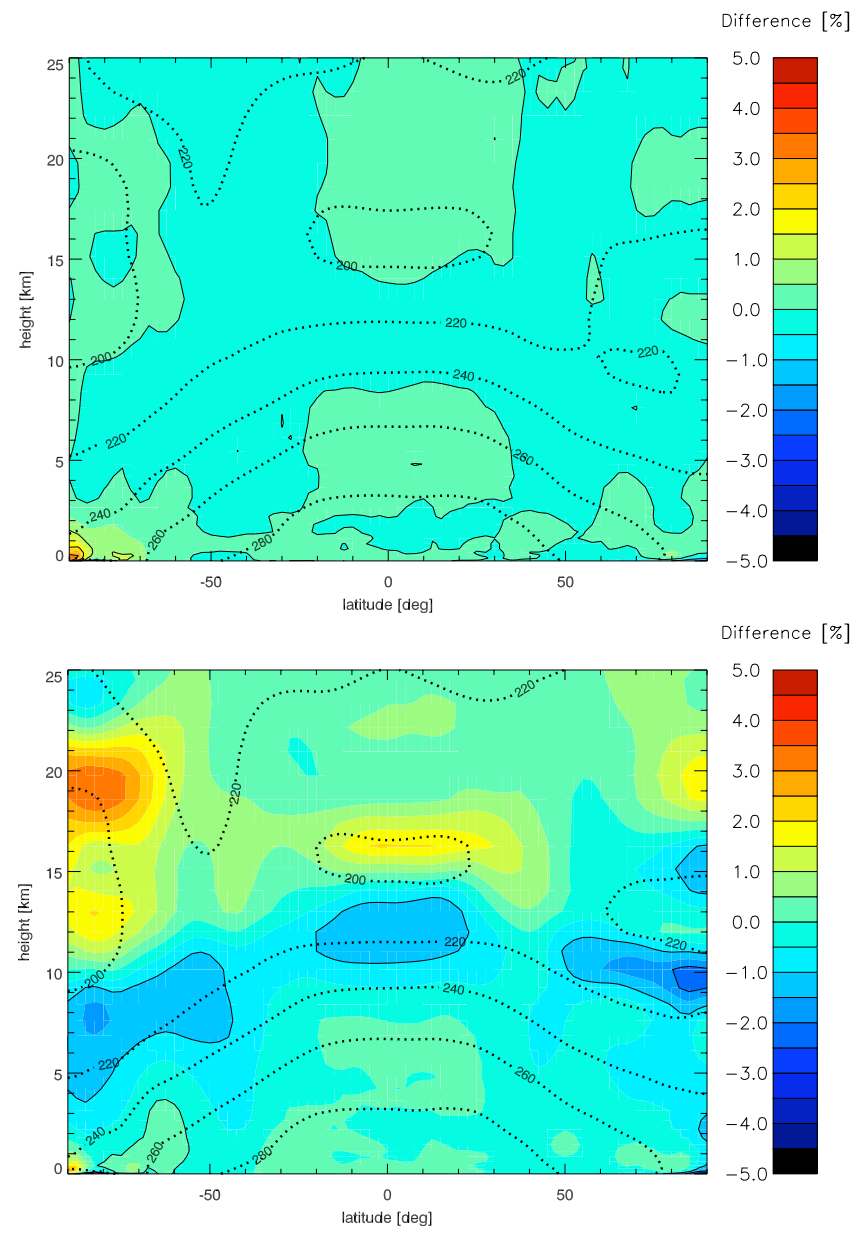

Fig. 4. Zonal mean bias in $\theta$ between the model and the ERA-40 data for October 1999. The top plot is with nudging and the bottom without. Isotherms from ERA-40 are included for reference.

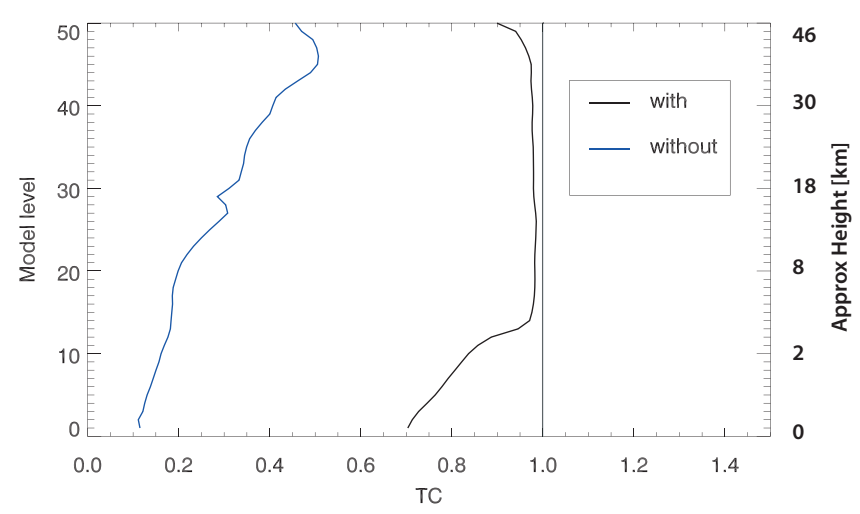

Fig. 5. TC for $u$ between the model and the ERA-40 data as a function of UM hybrid height level, with and without nudging, in October 1999. The maximum possible value that TC can take, 1, is shown for reference.
Table 3. Statistical Assessments for $\omega$ with (w) and without (w/o) nudging.

\begin{tabular}{ccccccc}
\hline \multirow{2}{*}{ Level } & \multicolumn{2}{c}{ RMSE $\left(\mathrm{Pa} \mathrm{s}^{-1}\right)$} & \multicolumn{2}{c}{ TC } & \multicolumn{2}{c}{ SC } \\
& w & w/o & w & w/o & w & w/o \\
\hline $925 \mathrm{hPa}$ & 0.10 & 0.11 & 0.38 & 0.05 & 0.40 & 0.10 \\
$500 \mathrm{hPa}$ & 0.11 & 0.17 & 0.67 & 0.06 & 0.70 & 0.12 \\
$50 \mathrm{hPa}$ & 0.007 & 0.009 & 0.56 & 0.07 & 0.67 & 0.26 \\
$10 \mathrm{hPa}$ & 0.003 & 0.003 & 0.52 & 0.07 & 0.53 & 0.19 \\
\hline
\end{tabular}

Table 4. Precipitation in October 1999 with and without nudging.

\begin{tabular}{lcccc}
\hline & Mean and Bias & RMSE & TC & SC \\
\hline with nudging & $2.44-0.14 \mathrm{~mm}$ & $5.4 \mathrm{~mm}$ & 0.56 & 0.59 \\
without nudging & $2.45-0.14 \mathrm{~mm}$ & $7.2 \mathrm{~mm}$ & 0.26 & 0.11 \\
\hline
\end{tabular}

Ocean disappear with the addition of nudging. This is a result of the synoptic scale systems being nudged into the same phase as in the ERA-40 data. The differences in orography can also be seen, especially on the edge of Antarctica. These are responsible for the high RMSE for $P_{S}$ in the model, as seen in Tables 1 and 2 .

The differences in the SC with and without nudging are not as dramatic as those in the TC. This is as a result of the unadjusted model reproducing the spatial variation of quantities such as temperature and pressure reasonably well on a global scale. For a variable, such as $u$, in which the spatial variation is not reproduced so well in the unadjusted model, the addition of nudging produces significant increases in the correlation.

\subsection{Comparison of derived quantities}

In addition to the variables assessed in Sect. 3.1 two other quantities are examined, precipitation and the vertical wind (defined here as $\omega \equiv \frac{d P}{d t}$ ). The precipitation is derived differently in both models, so differences are expected due to different treatment of model physics. The vertical wind is a derived quantity in the ECMWF model, but in the UM it is a prognostic quantity, which could result in further differences. In addition the ERA-40 data contains some significant biases, most notably an excess of precipitation over tropical oceans (Uppala et al., 2005). In spite of these difficulties these variables are studied as they can be used to confirm that the model is producing large scale atmospheric motions more like those in the ERA-40 data.

The vertical wind was studied by comparing $\omega$ on the ECMWF fixed pressure levels. This is done by calculating RMSE, TC and SC on pressure levels that approximate to 


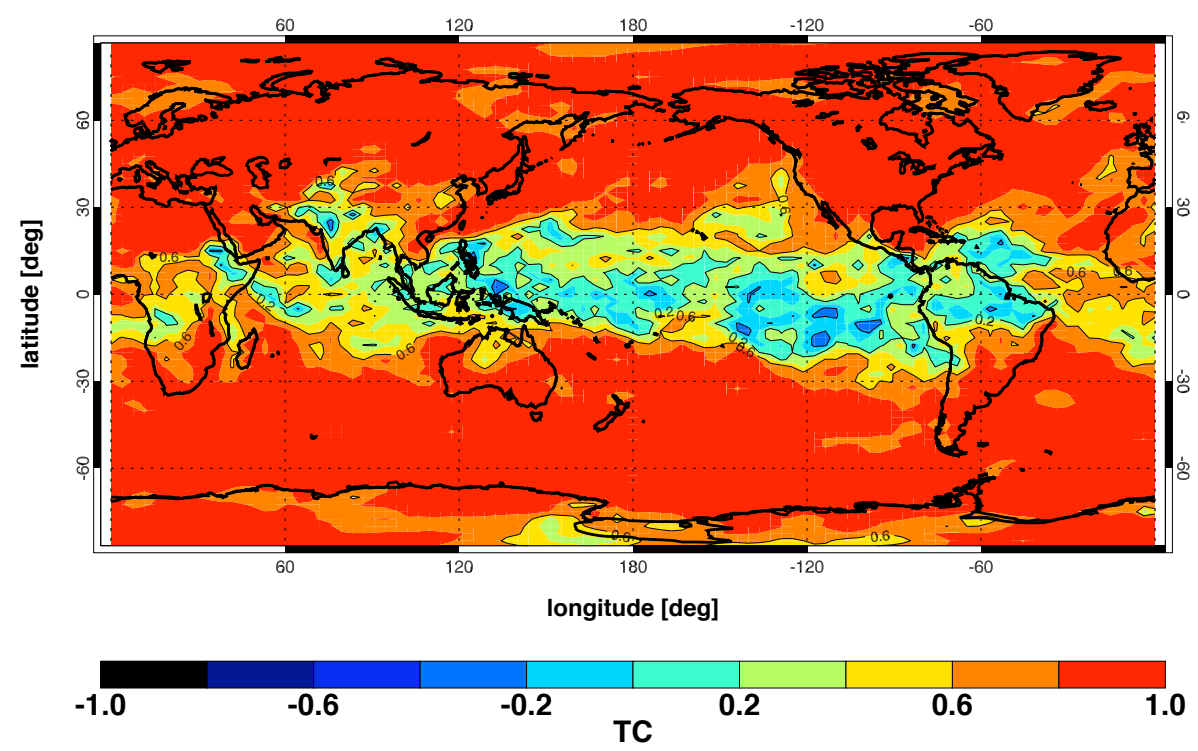

Fig. 6. TC for $\theta$ between the model, with nudging, and the ERA-40 data for UM hybrid height level 6 ( 700 m) in October 1999.

the UM hybrid height levels used in Sect. 3.1, which are displayed in Table 3.

The addition of nudging makes the vertical winds more closely resemble those in ERA-40 data, but there are still large differences, which are not unexpected considering the differences between the UM and ECMWF models. Figure 8 shows the TC for $\omega$ at a fixed pressure level of $500 \mathrm{hPa}$. The same pattern observed in Fig. 6 is seen, with good agreement in the extra-tropics.

The quantitative assessments used in Sect. 3.1 were applied to the precipitation, as listed in Table 4. The RMSE between the model and then ERA-40 data is shown in Fig. 9. The addition of nudging reduces the differences between the model and the analyses, especially in the extra-tropics. Much of the remaining differences in the tropics can be attributed to errors in the precipitation in the ERA-40 data.

The addition of nudging produces better agreement between the model and the ERA-40 data, especially in the extra-tropics. This reflects the synchronisation of the large scale motion in the model with the ERA-40 data. Much of the remaining differences can be attributed to differences in model physics between the UM and ECMWF models.

\subsection{Effects on the model dynamics}

The addition of nudging could potentially adversely affect the model dynamics, either by a mismatch with the dynamics in the re-analysis or in the addition of spurious "noise". Any large alteration of the circulation of the model would probably disrupt the vertical winds. The demonstration, in Sect. 3.2, that the vertical wind provides better agreement with the analyses with the addition of nudging increases con-
Table 5. Ratio of tendencies in variables between nudging and all other tendencies.

\begin{tabular}{ccccc}
\hline & Level & October & January & July \\
\hline & $16(\sim 5 \mathrm{~km})$ & 0.16 & 0.16 & 0.15 \\
$\theta$ & $29(\sim 15 \mathrm{~km})$ & 0.36 & 0.47 & 0.39 \\
& $35(\sim 20 \mathrm{~km})$ & 0.30 & 0.36 & 0.43 \\
& & & & \\
& $16(\sim 5 \mathrm{~km})$ & 0.37 & 0.39 & 0.43 \\
$u$ & $29(\sim 15 \mathrm{~km})$ & 0.29 & 0.40 & 0.43 \\
& $35(\sim 20 \mathrm{~km})$ & 0.30 & 0.37 & 0.43 \\
\hline
\end{tabular}

fidence that the model has not been disturbed by the nudging. It is not realistic to make these checks for all aspects of the model, so checks should be made when using variables not described above.

Another check made was to compare the tendency due to nudging to that from all other tendencies for $\theta$ and $u$. This is done by calculating the ratio between the magnitude of these two tendencies, as summarised in Table 5. These values are averaged over all grid-points in each UM hybrid height level and over all time-steps in the month.

There is a degree of variability in time and over the height range, but the tendency due to nudging is never larger than the tendency due to other factors. Figure 10 displays this ratio as a function of UM hybrid height levels for $\theta$ for the three assessment periods. The ratio tends to increase with height, showing that the UM has to be forced harder at higher altitudes to agree with the ERA-40 data. This agrees with the conclusions drawn from Fig. 2 that the UM and ECMWF models differ most in the upper stratosphere. 

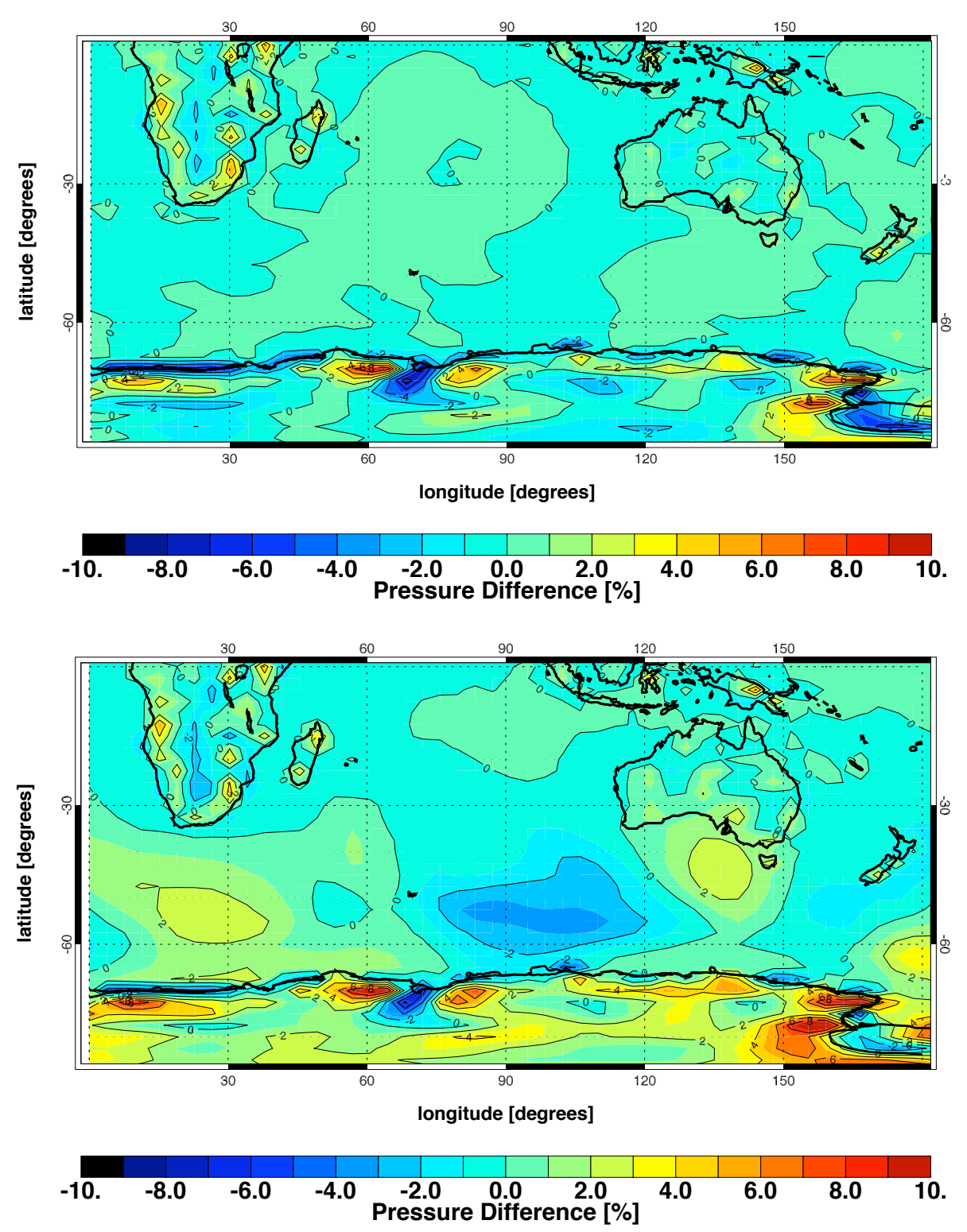

Fig. 7. Difference in surface pressure between the model and the ERA-40 data for a snapshot on 30 October 1999. The top plot shows this with nudging and the bottom without. The region displayed is the eastern half of the Southern Hemisphere.

\section{Sensitivity to model parameters}

The effect of varying some arbitrary nudging parameters is studied here. This is done by the same assessments used on the default nudging parameters in Sect. 3.1, which will now be denoted the standard assessments. The sensitivity is tested with respect to varying three key parameters: (i) the magnitude of the relaxation parameter used; (ii) the height above which nudging is turned off; and (iii) the ERA-40 data is interpolated from ECMWF fixed pressure levels rather than the original ECMWF hybrid pressure levels. This is designed to test our sensitivity to the interpolation in height.
The first sensitivity study was to vary the strength of the relaxation parameter $(G)$ used. Month long runs were made in October 1999 with $G$ reduced by a factor of 10, the weakly nudged run, and increased by a factor of 10 , the strongly nudged run. The results of these runs were analysed using the standard assessments. The results are tabulated in Table 6 for the weakly nudged run and Table 7 for the strongly nudged run. Comparing to Tables 1 and 2, the weakly nudged run produces better agreement than the run without nudging, but not as good agreement as the standard nudging. The strongly nudged run produces better agreement where the variable is being nudged, but there is no evidence of significant change 


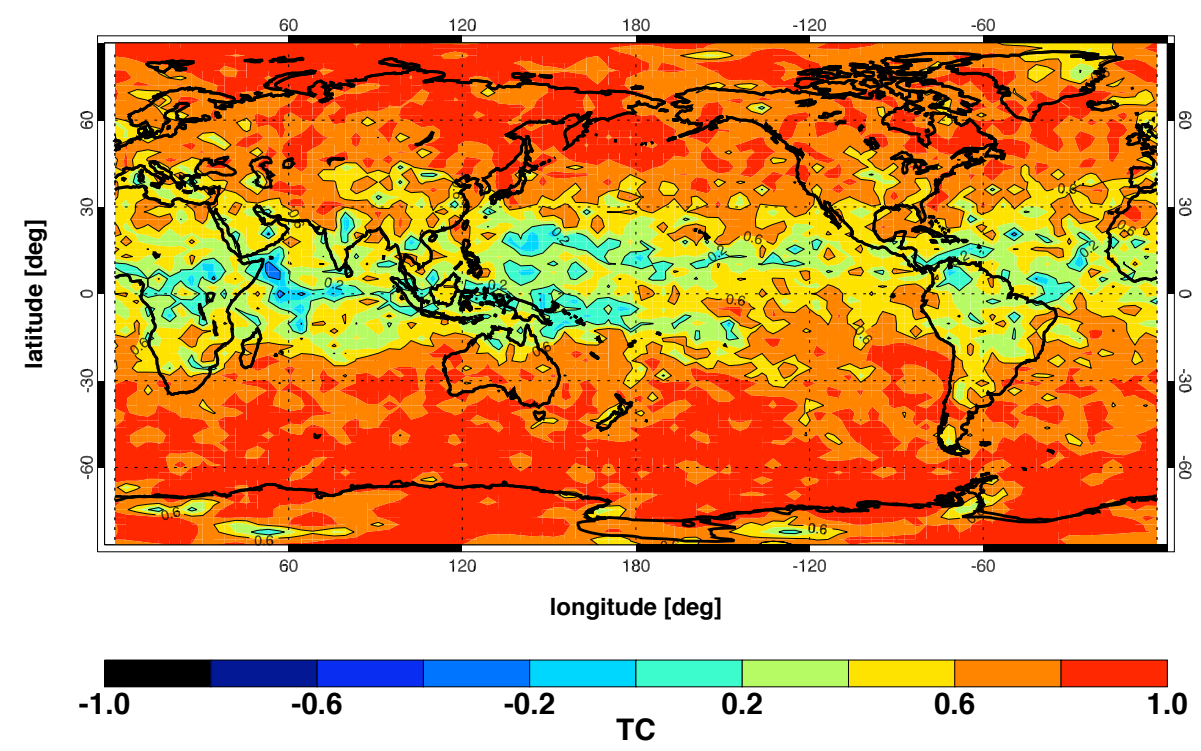

Fig. 8. TC for $\omega$ between the model, with nudging, and the ERA-40 data for fixed pressure level of $500 \mathrm{hPa}$ in October 1999.

Table 6. Quantitative assessment of model performance in October 1999 with weak nudging.

\begin{tabular}{cccccc}
\hline & Level & Mean and Bias & RMSE & TC & SC \\
\hline \multirow{4}{*}{$\theta$} & 6 & $284.9-0.2 \mathrm{~K}$ & $3.3 \mathrm{~K}$ & 0.54 & 0.97 \\
& 16 & $305.8-0.7 \mathrm{~K}$ & $2.6 \mathrm{~K}$ & 0.72 & 0.99 \\
& 29 & $416.7+0.0 \mathrm{~K}$ & $2.9 \mathrm{~K}$ & 0.86 & 0.99 \\
& 35 & $607.9-0.7 \mathrm{~K}$ & $3.5 \mathrm{~K}$ & 0.85 & 0.99 \\
& 6 & & & & \\
4 & 16 & $6.97-0.06 \mathrm{~ms}^{-1}$ & $5.5 \mathrm{~ms}^{-1}$ & 0.52 & 0.77 \\
& 29 & $12.87-0.05 \mathrm{~ms}^{-1}$ & $3.0 \mathrm{~ms}^{-1}$ & 0.76 & 0.90 \\
& 35 & $10.45+0.07 \mathrm{~ms}^{-1}$ & $2.7 \mathrm{~ms}^{-1}$ & 0.87 & 0.97 \\
& 6 & & & & 0.93 \\
& 16 & $0.9+0.0 \mathrm{~g} / \mathrm{kg}$ & $0.9 \mathrm{~g} / \mathrm{kg}$ & 0.49 & 0.75 \\
& 29 & $2.4+0.0 \mathrm{mg} / \mathrm{kg}$ & $0.3 \mathrm{mg} / \mathrm{kg}$ & 0.10 & 0.85 \\
& 35 & $2.5-0.1 \mathrm{mg} / \mathrm{kg}$ & $0.3 \mathrm{mg} / \mathrm{kg}$ & -0.09 & 0.19 \\
& & & & & \\
$P_{S}$ & 0 & $964.3+0.9 \mathrm{hPa}$ & $14.6 \mathrm{hPa}$ & 0.71 & 0.99 \\
\hline
\end{tabular}

in the variables and regions that are not nudged. The ratios of the tendencies due to nudging and all other factors for the strongly and weakly nudged runs are given in Table 8 . The table suggests that, for the strongly nudged run, the nudging becomes the dominant tendency.

The evidence indicates that the relaxation parameter chosen originally is a reasonable choice, producing significant improvement in the description of the ERA-40 data without predominating over the model's physical tendencies.
Table 7. Quantitative assessment of model performance in October 1999 with strong nudging.

\begin{tabular}{cccccc}
\hline & Level & Mean and Bias & RMSE & TC & SC \\
\hline \multirow{4}{*}{$\theta$} & 6 & $285.8+0.8 \mathrm{~K}$ & $2.6 \mathrm{~K}$ & 0.77 & 0.98 \\
& 16 & $306.6+0.0 \mathrm{~K}$ & $0.2 \mathrm{~K}$ & 0.99 & 1.00 \\
& 29 & $416.0+0.0 \mathrm{~K}$ & $0.3 \mathrm{~K}$ & 1.00 & 1.00 \\
& 35 & $607.6+0.0 \mathrm{~K}$ & $0.8 \mathrm{~K}$ & 0.99 & 1.00 \\
& 6 & & & & \\
4 & 16 & $6.05-0.01 \mathrm{~ms}^{-1}$ & $0.40 \mathrm{~ms}^{-1}$ & 1.00 & 1.00 \\
& 29 & $12.96+0.01 \mathrm{~ms}^{-1}$ & $0.46 \mathrm{~ms}^{-1}$ & 1.00 & 1.00 \\
& 35 & $10.38+0.01 \mathrm{~ms}^{-1}$ & $0.59 \mathrm{~ms}^{-1}$ & 1.00 & 1.00 \\
& 6 & & & & \\
& 16 & $1.0+0.1 \mathrm{~g} / \mathrm{kg}$ & $0.7 \mathrm{~g} / \mathrm{kg}$ & 0.78 & 0.88 \\
& 29 & $2.4+0.0 \mathrm{mg} / \mathrm{kg}$ & $0.4 \mathrm{mg} / \mathrm{kg}$ & 0.30 & 0.80 \\
& 35 & $2.5-0.1 \mathrm{mg} / \mathrm{kg}$ & $0.3 \mathrm{mg} / \mathrm{kg}$ & -0.12 & 0.24 \\
& & & & & \\
$P_{S}$ & 0 & $963.9+0.4 \mathrm{hPa}$ & $15.4 \mathrm{hPa}$ & 0.93 & 0.99 \\
\hline
\end{tabular}

We apply nudging to as great a height possible, only excluding where the quality of the ERA-40 data becomes doubtful. The ECHAM model ${ }^{3}$ has been run in a configuration where the nudging is applied in the troposphere alone and see little difference to the case where nudging is applied into the stratosphere (Jöckel et al., 2006). We perform a similar exercise by turning nudging off above model level 31

\footnotetext{
${ }^{3}$ Version ECHAM5/MESSy1
} 

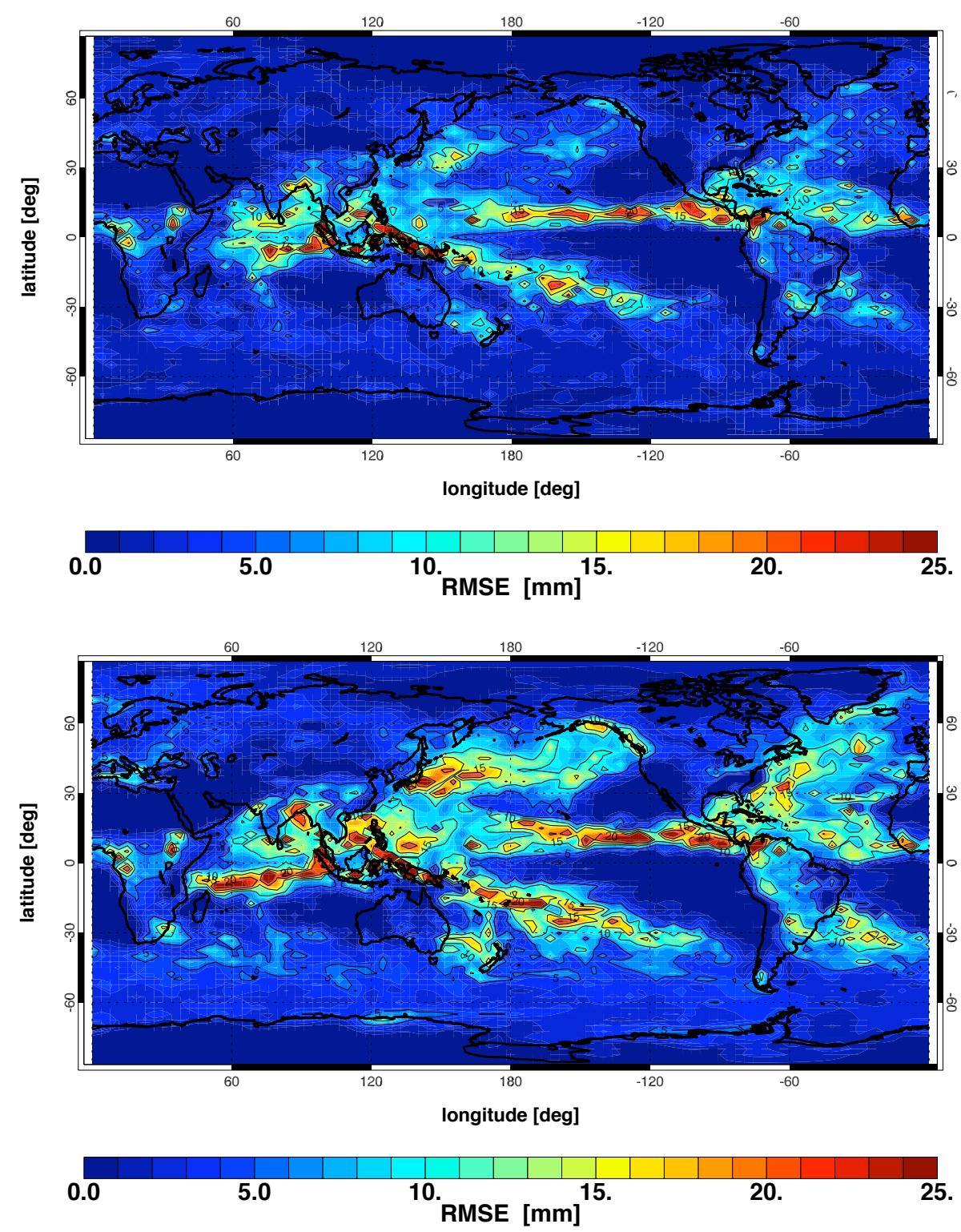

Fig. 9. RMSE for precipitation between the model and the ERA-40 data in October 1999. The top plot is with and the bottom plot without nudging.

Table 8. Ratio of tendencies in variables between nudging and all other tendencies for the strongly and weakly nudged runs.

\begin{tabular}{ccccc}
\hline \multirow{2}{*}{ Level } & \multicolumn{2}{c}{$\theta$} & \multicolumn{2}{c}{$u$} \\
& strong & weak & strong & weak \\
\hline $16(\sim 5 \mathrm{~km})$ & 0.61 & 0.09 & 0.83 & 0.15 \\
$29(\sim 15 \mathrm{~km})$ & 0.92 & 0.14 & 1.02 & 0.18 \\
$35(\sim 20 \mathrm{~km})$ & 1.01 & 0.10 & 1.11 & 0.09 \\
\hline
\end{tabular}

( $\sim 19 \mathrm{~km}$ ), above the tropical tropopause. The standard assessments were performed again, producing results very similar to those in Sect. 3.1 in the lowest three assessed levels, but differ on the highest assessed level, level $35(\sim 20 \mathrm{~km})$, from which the results are tabulated in Table 9 . There is still considerable improvement with respect to the case with no nudging, but not enough to justify using this lower cut-off.

The ERA-40 data is originally produced on hybrid pressure levels but is made available interpolated onto a set of fixed pressure levels. The last study is to take the ERA-40 data on these fixed pressure levels. 


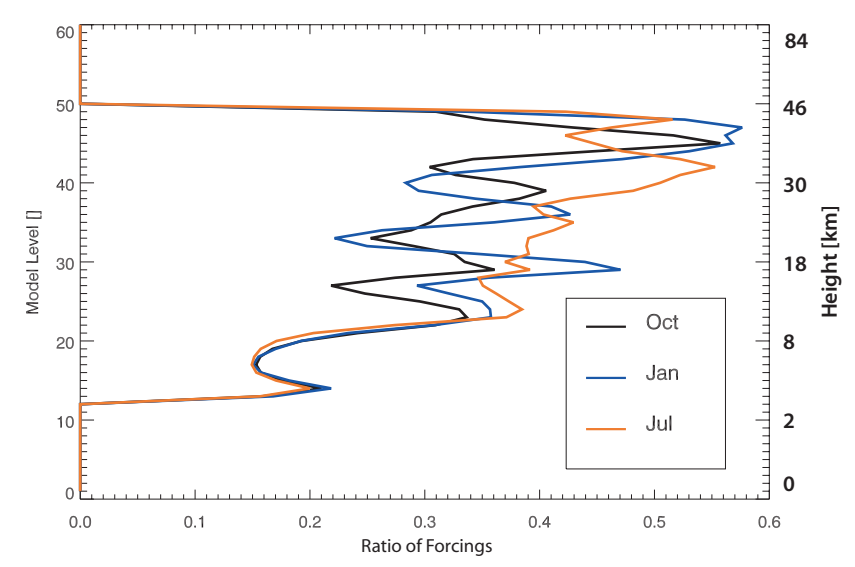

Fig. 10. Ratio of tendency due to nudging to all other tendencies for $\theta$ for October 1999 and January and July 2000.

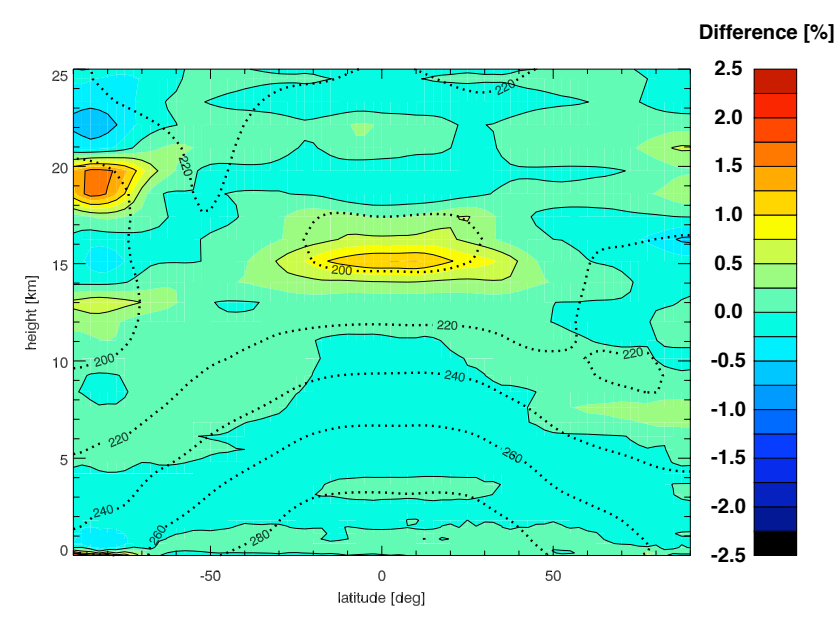

Fig. 11. Zonal mean difference in $\theta$ on UM hybrid height levels between ERA-40 data on fixed pressure levels and hybrid pressure levels. Isotherms from ERA-40 are included for reference.

A run is made for October 1999 and the standard assessments made. If we compare the model output to the ERA-40 data on fixed pressure levels interpolated on to UM hybrid height levels we see results that are similar to those seen in Sect. 3.1. However if we compare the model output to ERA40 data on the hybrid pressure levels interpolated on to the UM hybrid height levels we see discrepancies. These differences result from the additional interpolation to produce the ERA-40 data on fixed pressure levels. They are insignificant in the troposphere, but produce significant differences around the tropopause and above, in regions where the gradient is steep, such as the tropical tropopause and just below $20 \mathrm{~km}$ above Antarctica. The gentler vertical gradients in $u$ and $v$ result in much smaller differences.

The differences produced by this additional interpolation also give an indication of sensitivity to the interpolation of
Table 9. Quantitative assessment for model level $35(\sim 20 \mathrm{~km})$ in October 1999 with "tropospheric only" nudging.

\begin{tabular}{ccccc}
\hline & Mean and Bias & RMSE & TC & SC \\
\hline$\theta$ & $606.0-1.0 \mathrm{~K}$ & $6.6 \mathrm{~K}$ & 0.69 & 0.97 \\
$u$ & $9.96-0.41 \mathrm{~ms}^{-1}$ & $3.63 \mathrm{~ms}^{-1}$ & 0.88 & 0.98 \\
$q$ & $2.5-0.1 \mathrm{mg} / \mathrm{kg}$ & $0.3 \mathrm{mg} / \mathrm{kg}$ & -0.11 & 0.26 \\
\hline
\end{tabular}

the ERA-40 data onto the UM hybrid height levels. The small size of the differences throughout most of the atmosphere indicates that the interpolation is not introducing large errors.

\section{Conclusions}

We have described a nudged version of the "New Dynamics" Unified Model and demonstrate that it reproduces the ERA40 data better compared to the model without nudging. This is the first detailed description of the dynamics of a nudged grid-point model and we have noted similar features to those seen in nudged spectral models.

The addition of nudging reduces biases between the model and the ERA-40 data, such as those in $\theta$ in the stratosphere (Fig. 4). The variability of the ERA-40 data is demonstrated to be well reproduced (Fig. 5) with the addition of nudging, even in variables not directly adjusted such as $q$ and $\omega$ (Figs. 8 and 9). This reflects that the "weather" is reasonably well represented. The strength and height regime of nudging were varied to demonstrate that the parameters chosen are reasonable.

Future work will concentrate on the behaviour of tracers, with the nudged model being used to evaluate the new UK chemistry and aerosol (UKCA) chemistry climate model (CCM), which is also based on the UM. The removal of biases should aid the modelling of phenomena sensitive to the model dynamics, such as polar stratospheric cloud formation. A reasonable representation of the weather allows episodic data to be used, expanding the available data sets that can be used to evaluate the model.

In conclusion the addition of nudging allows better correspondence with global meteorological re-analysis data to be obtained and will provide a powerful tool for studying aspects of the UM on short time-scales.

Acknowledgements. This work was supported by NCAS. We also acknowledge support through the EU FP6 Integrated Programme, SCOUT-O3.

Edited by: M. Dameris 


\section{References}

Brill, K., Uccellini, L., Manobianco, J., Kocin, P., and Homan, J.: The use of successive dynamic initialization by nudging to simulate cyclogenesis during GALE-IOP, 1, Meteorol. Atmos. Phys., 45, 15-40, 1991.

Dean, S. M., Flowerdew, J., Lawrence, B. N., and Eckermann, S. D.: Parameterisation of orographic cloud dynamics in a GCM, Clim. Dynam., 28, 581-597, 2006.

ECMWF: The Description of the ECMWF Re-analysis Global Atmospheric Data Archive, ECMWF, 1996.

Hauglustaine, D., Hourdin, F., Jourdain, L., Filliberti, M., Walters, S., Lamarque, J., and Holland, E.: Interactive chemistry in the Laboratoire de Météorolgie Dynamique general circulation model: Description and background tropospheric chemistry evaluation, J. Geophys. Res., 109, 4314, doi:10.1029/2003JD003957, 2004.

Jeuken, A., Siegmund, P., Heijboer, L., Feichter, J., and Bengtsson, L.: On the Potential of assimilating meteorological analyses in a global climate model for the purposes of model validation, J. Geophys. Res., 101, 16939-16 950, 1996.

Jöckel, P., Tost, H., Pozzer, A., Brühl, C., Buchholz, J., Ganzeveld, L., Hoor, P., Kerkweg, A., Lawrence, M.G., Sander, R., Steil, B., Stiller, G., Tanarhte, M., Taraborrelli, D., van Aardenne, J., and Lelieveld, J.: The atmospheric chemistry general circulation model ECHAM5/MESSy1: consistent simulation of ozone from the surface to the mesosphere, Atmos. Chem. Phys., 6, 50675104, 2006, http://www.atmos-chem-phys.net/6/5067/2006/.

Lorenc, A., Andrews, P., Ballard, S., Clayton, A., Ingleby, N., Li, D., Payne, T., and Saunders, F.: Design and Testing of the Met Office Variational Data Assimilation Scheme, Technical Report 262, Met Office, 1999.

Pyle, J. A., Braesicke, P., and Zeng, G.: Dynamical variability in the modeling of chemistry-climate interactions, Faraday Discuss., 130, 27-39, 2005.

Rayner, A., Parker, D., Horton, E., Folland, C., Alexander, L., Rowell, D., Kent, E., and Kaplan, A.: Global analyses of sea surface temperature, sea ice, and night marine air temperature since the late nineteenth century, J. Geophys. Res., 108D, 4407, doi:10.1029/2000JD900205, 2003.
Schmidt, G., Ruedy, R., Hansen, J., Aleinov, I., Bell, N., Bauer, M., Bauer, S., Cairns, B., Canuto, V., Cheng, Y., Del Genio, A., Faluvegi, G., Friend, A., Hall, T., Hu, Y., Kelley, M., Kiang, N., Koch, D., Lacis, A., Lerner, J., Lo, K., Miller, R., Nazarenko, L., Oinas, V., Perlwitz, J., Perlwitz, J., Rind, D., Romanou, A., Russell, G., Sato, M., Shindell, D., Stone, P., Sun, S., Tausnev, N., Thresher, D., and Yao, M.-S.: Present day atmospheric simulations using GISS ModelE: Comparison to in-situ, satellite and reanalysis data, J. Climate, 19, 153-192, 2006.

Staniforth, A., White, A., Wood, N., Thuburn, J., Zerroukat, M., Cordero, E., and Davies, T.: Joy of U.M. 6.1 - Model Formulation, United Kingdom Meteorological Office (UKMO), 2005.

Takemura, T., Okamoto, H., Maruyama, Y., Numaguti, A., Higurashi, A., and Nakajima, T.: Global three dimensional simulation of aerosol optical thickness distribution of various origins, J. Geophys. Res., 105, 17 853-17 873, 2000.

Uppala, S., Kallberg, P., Simmons, A., Andrae, U., da Costa Bechtold, V., Fiorino, M., Gibson, J., Haseler, J., Hernandez, A., Kelly, G., Li, X., Onogi, K., Saarinen, S., Sokka, N., Allan, R., Andersson, E., Arpe, K., Balmaseda, M., Beljaars, A., van de Berg, L., Bidlot, J., Bormann, N., Caires, S., Chevallier, F., Dethof, A., Dragosavac, M., Fisher, M., Fuentes, M., Hagemann, S., Holm, E., Hoskins, B., Isaksen, L., Janssen, P., Jenne, R., McNally, A., Mahfouf, J.-F., Morcrette, J.-J., Rayner, N., Saunders, R., Simon, P., Sterl, A., Trenberth, K., Untch, A., Vasiljevic, D., Viterbo, P., and Woollen, J.: The ERA-40 re-analysis, Q. J. Roy. Meteor. Soc., 131, 2961-3012, 2005.

van Aalst, M., van den Broeck, M., Bregman, A., Brühl, C., Steil, B., Toon, G., Garcelon, S., Hansford, G., Jones, R., Gardiner, T., Roelofs, G., Lelieveld, J., and Crutzen, P.: Trace Gas Transport in the 1999/2000 Arctic winter: comparison of nudged GCM runs with observations, Atmos. Chem. Phys., 4, 81-93, 2004, http://www.atmos-chem-phys.net/4/81/2004/. 